\title{
Thyroid cancer incidence in Canada: a national cancer registry analysis
}

\author{
Dawnelle Topstad MD MPH, James A. Dickinson MBBS PhD
}

\section{Abstract}

Background: Thyroid cancer incidence rates are increasing in many developed countries while mortality rates remain stable. International evidence shows that the increase in incidence rates is mostly caused by overdiagnosis of small papillary cancers. We sought to describe how thyroid cancer incidence has changed and how it varies between provinces in Canada.

Methods: Data were obtained from the National Cancer Incidence Reporting System, causes of death tables and the Canadian Cancer Registry using the 1991 census population structure. We report thyroid cancer incidence by sex, age and province and mortality by sex from 1970 to 2012.

Results: Since 1970, age-standardized thyroid cancer incidence rates have increased in women from 3.9 to 23.4 per 100000 and in men from 1.5 to 7.2 per 100000 while mortality rates have remained stable at around 0.5 per 100000 for both sexes. In 2012 , incidence rates for both women and men were highest in Ontario (31.5 and 9.2 per 100000 , respectively) and lowest in British Columbia (13.2 and 4.5 per 100 000, respectively). Age-specific incidence rates were the highest in Ontarian women aged 50-54 years, at 65.2 per 100000 .

Interpretation: The rapid increase in thyroid cancer incidence especially since 1990, the variation among provinces and the peak in middle-aged women does not correspond to any known cause or risk factor for disease, although the lack of change in mortality rates suggests that serious thyroid cancer has not increased. The likely cause of the increase in incidence is an overdiagnosis epidemic for clinically unimportant lesions detected by modern diagnostic imaging. To reduce the harms of overtreatment, overdiagnosis should be reduced, through more judicious use of diagnostic imaging.

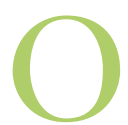
ver the past several decades, thyroid cancer incidence rates have been increasing in many highincome countries. ${ }^{1-4}$ The largest increase has occurred in middle-aged women; incidence rates in men have varied less. Thyroid cancer mortality rates have varied minimally. ${ }^{4}$ This pattern of increasing thyroid cancer incidence rates and stable mortality rates has also been seen in Canada. In 2016, thyroid cancer was predicted to be the fifth most common cancer in Canadian women after breast, lung, colon and uterine cancers, with 5273 cases accounting for $5.3 \%$ of cancers in women. It was predicted to be the 16th most common cancer in men, with 1543 cases accounting for $1.5 \%$ of cancers in men. ${ }^{5}$ However, the survival ratio is over $98 \%$ for women and $95 \%$ for men, with only about 120 women and 90 men dying of all types of thyroid cancer each year. ${ }^{5}$

There are 4 histological types of thyroid cancer: papillary, follicular, medullary and anaplastic, with papillary being the most common. ${ }^{6}$ Most of the recent increase in incidence is due to papillary thyroid cancer, ${ }^{1,3,4}$ which generally has an indolent course; only a small proportion of these cancers behave aggressively and very few patients die. ${ }^{7}$ There is thus the potential for overdiagnosis and overtreatment of lesions that if left alone would never cause any problems. ${ }^{8}$ Choosing Wisely Canada has indicated that the early detection of small thyroid lesions contributes to overdiagnosis and suggests limiting use of thyroid ultrasound. ${ }^{9}$ Given different practice patterns among provinces, overdiagnosis may occur more frequently in some areas than others. We therefore aim to understand thyroid cancer incidence and mortality trends in Canada and across provinces. We examined how much variation in incidence exists across the country and whether there is any reason for this variation.

Competing interests: None declared.

This article has been peer reviewed.

Correspondence to: James Dickinson, dickinsj@ucalgary.ca

CMAJ Open 2017. DOI:10.9778/cmajo.20160162 


\section{Methods}

\section{Setting}

We obtained Canadian national and provincial population data to describe thyroid cancer incidence and mortality (International Classification of Diseases, 9th revision [ICD-9] code 193, and ICD-10 code C73).

\section{Design}

Age-standardized incidence rates for thyroid cancer from 1970 to 2012 were analyzed by sex, province and age using the Canadian 1991 census population structure (the standard used before the 2016 release of Canadian Cancer Statistics) to enable comparison with prior work. ${ }^{10}$

\section{Data sources}

All incidence data were reported to the National Cancer Incidence Reporting System of Statistics Canada until 1991. Since 1992, incidence data have been reported to the Canadian Cancer Registry. Mortality data were reported in the causes of death tables until 1999; since 2000 they have been reported to the Canadian Cancer Registry. ${ }^{11,12}$ The quality of the data from the National Cancer Incidence Reporting System before 1983 varies because of inconsistencies in reporting. ${ }^{6}$ The quality of Canadian Cancer Registry data has been documented with over $90 \%$ of the thyroid cancer pathology being confirmed on 2 occasions. ${ }^{13}$

\section{Analysis}

Age-standardized incidence and mortality rates were calculated on the basis of population data published by Statistics Canada, ${ }^{14}$ using Excel spreadsheets. Because of privacy rules, cell counts less than 5 are not released. Therefore, because of small cell sizes, we could not calculate provincial mortality rates, only national ones. Another consequence of small cell numbers was that we could not calculate incidence rates for all 43 years of our study period in smaller provinces (Saskatchewan, Manitoba and the Atlantic provinces) and the territories. Therefore, for comparison between provinces, we graphed only the data from the 4 provinces with the largest populations (Ontario, Quebec, Alberta and British Columbia).

\section{Results}

Over the 43 years of our study period, age-standardized thyroid cancer incidence rates in Canada increased by almost 6 times in women (from 3.9 to 23.4 per 100000 ) and 5 times in men (from 1.5 to 7.2 per 100000 ) as shown in Figure 1.11,12 Age-standardized mortality rates varied minimally, with the highest rate being 0.84 per 100000 in 1971 and the lowest rate being 0.32 per 100000 in 1988 . Numbers were too small to permit calculating age-standardized mortality rates by sex, but crude mortality rates were stable, varying between 0.42 and 0.80 per 100000 in women and between 0.16 and 0.59 per 100000 in men over the study period. Most of the women and men who died were over 60 years of age.
Figure 2 maps 2012 incidence rates for men and women across the 10 Canadian provinces. The 3 territories were excluded because data were not released for these jurisdictions owing to the small size of their populations. Ontario and Newfoundland had the highest incidence rates in 2012, while BC, Saskatchewan, Nova Scotia and Prince Edward Island had the lowest rates. ${ }^{11}$ Appendix 1 (supplemental Figure S1, available at www.cmajopen.ca/content/5/3/E612/suppl/DC1) shows incidence rates for the study period for the 4 largest provinces, and Appendix 2 (supplemental Table S1, available at www. cmajopen.ca/content/5/3/E612/suppl/DC1) shows the incidence rates from all provinces in 1972, 1992 and 2012.

Figure 3 shows age-specific incidence rates in Canada by sex in 1972, 1992 and 2012. In 1972, incidence rates increased slowly with increasing age in both men and women, although the rates in women increased more quickly and to a greater degree across the age groups than in men. In 1992, the rates for men had barely changed from those in 1972, but they had doubled for women, starting from about age 30. In 2012, male rates still rose steadily until age 80 , but they were much higher at all ages, with an initial rise in the third decade of life. For women, rates now began to rise in the teenage years, increased rapidly through young adulthood, peaked at 43 per 100000 between 40 and 60 years of age, then dropped steadily at older ages. Appendix 3 (supplemental Figure S2, available at www.cmajopen.ca/ content/5/3/E612/suppl/DC1) shows age-specific incidence rates in Ontario; in 2012, incidence rates in that province peaked at over 60 per 100000 in women aged 50-54 years.

\section{Ethics approval}

Ethics review was not required, as non-identifiable, publicly available data were used in the study.

\section{Interpretation}

Over the 43 years of the study period, age-standardized thyroid cancer incidence rates in Canada increased by almost 6 times in women and 5 times in men, with the greatest absolute increase seen in women. Despite the increasing incidence

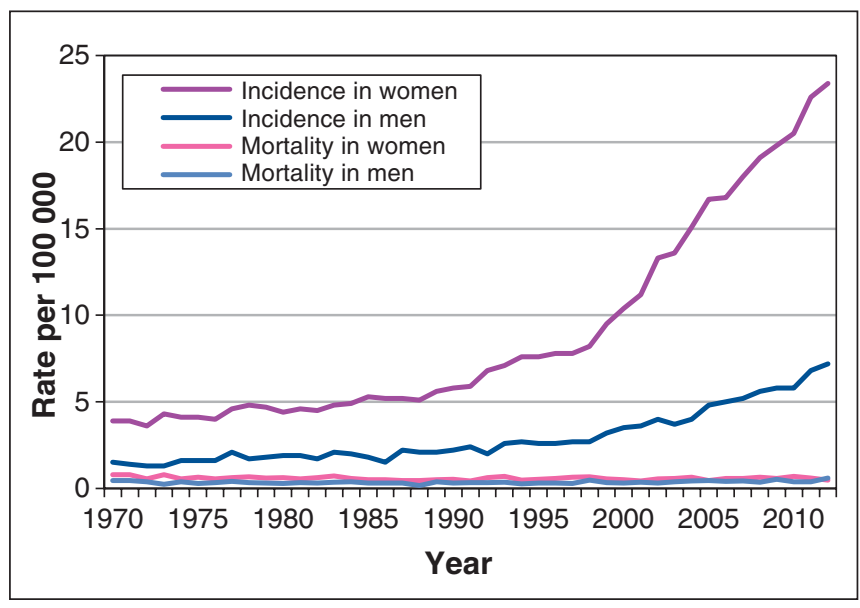

Figure 1: Age-standardized incidence rates and crude mortality rates for thyroid cancer in Canada from 1970 to 2012, by sex. 
rates, mortality remained stable and low for both sexes at approximately 0.5 per 100000 . However, between 1992 and 2012, incidence rates varied dramatically between provinces and even between regions within a province, as reported in Ontario. ${ }^{15}$ In 2012, the highest incidence rates were in Ontario; BC had the lowest rates, at about half those in Ontario. The age-specific incidence curve had also dramatically changed, especially for women, and its shape differed among provinces. Before the early 1990s, there was a gradual increase in thyroid cancer incidence rates with age, but more recently there was a peak incidence in 40- to 60-year-old women, which was over twice as high in Ontario as in BC.

Vaccarella and colleagues published similar findings showing substantial increases in thyroid cancer incidence especially among middle-aged women from high-income countries in Europe, Asia and the United States, with similar variation in age-specific incidence curves. ${ }^{16,17}$ They attributed these increases to overdiagnosis of subclinical nodules from improved diagnostic technology and increased surveillance. Canada's rates and variability are similar to those reported in Europe, though less than those found in South Korea. ${ }^{3}$

Given the geographical extent of Canada, we considered possible risk factors that could vary enough to explain the differences in thyroid cancer incidence among provinces. Radiation is a known risk factor for thyroid cancer, and some suggest that increased radiation exposure is driving the increase in incidence. Radiation increases the risk of thyroid cancer mostly through exposure during childhood and adolescence. ${ }^{18}$ It is unlikely that dramatic differences in exposure to background radiation or medical radiation from diagnostic tests or therapies among provinces explain the differences in incidence we observed. Dietary iodine deficiency or excess has

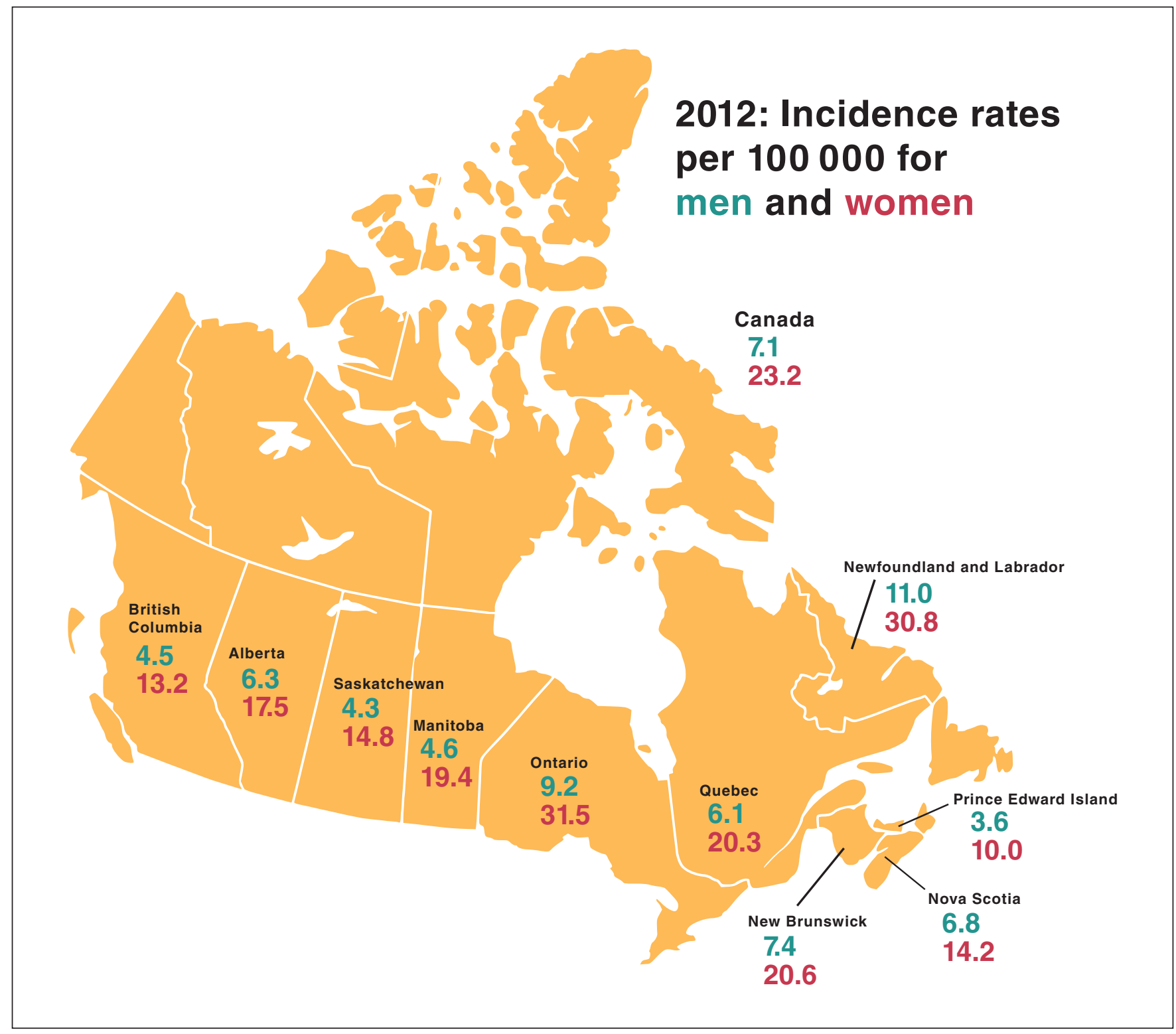

Figure 2: Age-standardized incidence rates for thyroid cancer by province in 2012. 


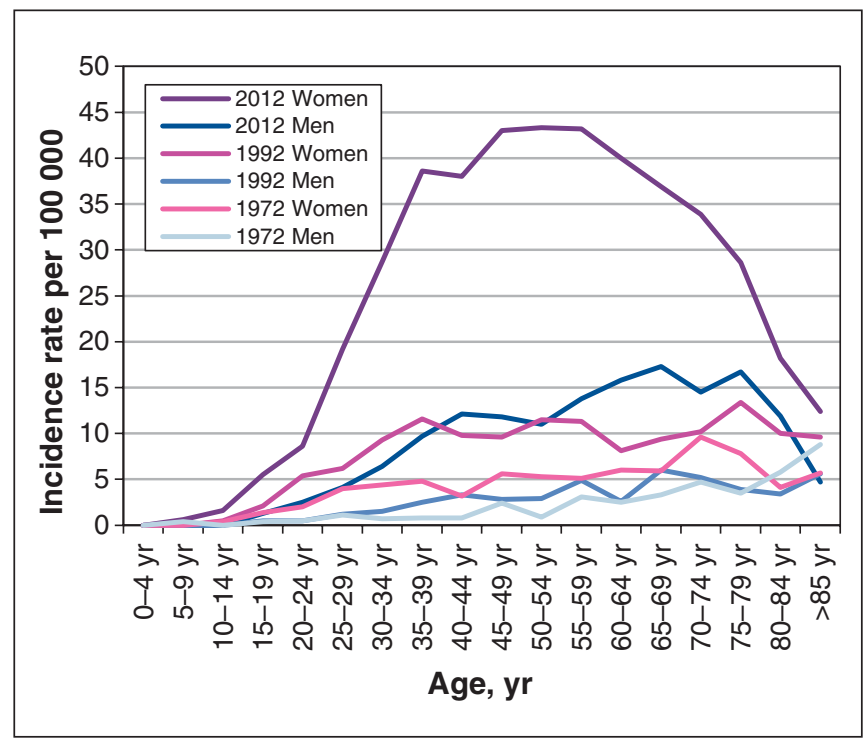

Figure 3: Age-specific incidence rates for thyroid cancer by sex in 1972, 1992 and 2012.

never been proven to have a causal role in thyroid cancer. ${ }^{19}$ Some speculate that obesity and diabetes may be associated with increasing incidence of thyroid cancer, but this association is still controversial and is confounded by increased use of diagnostic imaging leading to more detection. ${ }^{20,21}$ Within Canada, it is unlikely there is enough difference among provinces for any of these risk factors or genetic mutations to cause such a large and differential increase in thyroid cancer incidence.

If the increase in thyroid cancer incidence were real, one would expect an increase in symptomatic disease, late stages of disease and mortality. In Canada, as in many other highincome countries, the increase in thyroid cancer incidence is mostly due to asymptomatic cancers, and thyroid cancer mortality rates have not changed over the past several decades. ${ }^{6,22,23}$ If improved treatment for thyroid cancer is the reason for the mortality rates being constant, changes in treatment should coincide with the changing incidence. Despite debate over the past 40 years about the extent of surgery, the use of remnant radioactive iodine and suppressive thyroid hormone therapy, treatment protocols for thyroid cancer have not changed. ${ }^{24}$ With a much greater absolute increase in the incidence of thyroid cancer in women, treatment would need to be much more effective in women than in men for similar mortality rates to be observed in both sexes. Thyroid cancer treatment is identical for women and men, so it is unlikely that more effective treatment explains the stable mortality rates. The most likely explanation is that a consistent small number of potentially lethal thyroid cancers develop and may be ameliorated by the treatments, while many currently detected thyroid cancers either would not progress if untreated or would develop very slowly with minimal risk.

Overdiagnosis is the discovery of disease that would never cause symptoms or premature death if left untreated. In the absence of other explanations, the differing thyroid cancer incidence rates among Canadian provinces and the changes in the shape of the age-specific incidence curves are likely due to varying rates of overdiagnosis arising from differences in practice. In Ontario the use of ultrasound, computed tomography and magnetic resonance imaging increased $18 \%$ per year from 1993 to 2006, with women having 3 times more diagnostic imaging tests than men, except in the group over 60 years of age. ${ }^{25}$ This increasing use of imaging is mirrored by the increasing rates of thyroid cancer diagnosis, with the fourfold variation in diagnostic rates between regions correlating with patterns in the use of ultrasound, especially of the neck. ${ }^{15}$ Kent and colleagues ${ }^{22}$ found that the increase of thyroid cancer in Ontario is mainly due to small differentiated tumours, with the greatest increase in tumours less than $2 \mathrm{~cm}$, considered nonpalpable and subclinical. These findings support the hypothesis that the increased incidence rates of thyroid cancer are due to overdiagnosis, with cases discovered incidentally in small tumours. ${ }^{26}$ This reinforces the recommendation of Choosing Wisely Canada: “Don't routinely order a thyroid ultrasound in patients with abnormal thyroid function tests unless there is a palpable abnormality of the thyroid gland."

\section{Limitations}

The limitations of this study include variable data reporting to the National Cancer Incidence Reporting System before 1983. ${ }^{6}$ However, since the dramatic changes in incidence occurred after 1992, when the Canadian Cancer Registry was developed, we doubt this affects our results. The registry strives to achieve completeness, but reporting procedures still vary across the country. Quebec relies on hospital data, so the number of cases of some cancers may be underestimated in that province. Also, Quebec and Newfoundland have incomplete linkage between databases, resulting in underreporting. There can be delays in the provincial/territorial cancer registries updating the registry, and as a result recent data may be incomplete. The Canadian Cancer Registry is a dynamic database, so with each addition of data recent counts may vary. ${ }^{12}$ Another limitation is the difficulty in accessing the data for histology and size of thyroid cancers. Finally, data about the trends in use of diagnostic tests were not available for most provinces, so we were not able to compare them to correlate diagnostic intensity with incidence rates.

\section{Conclusion}

In Canada, there is great variation in thyroid cancer incidence rates among provinces, with a new pattern of rapidly increasing incidence affecting mostly women aged $40-60$ years. With such variation in incidence rates among provinces within one country, the thyroid cancer epidemic in Canada is most likely due to overdiagnosis, and the differences in incidence rates probably relate to different practice patterns among provinces. This overdiagnosis has appropriately been targeted by Choosing Wisely Canada. Further effort should concentrate on reducing overuse of diagnostic imaging and finding better ways to distinguish those patients with unimportant indolent tumours, while still identifying aggressive thyroid cancer that needs treatment. 


\section{References}

1. La Vecchia C, Malvezzi M, Bosetti C, et al. Thyroid cancer mortality and incidence: a global overview. Int 7 Cancer 2015;136:2187-95.

2. Chen AY, Jemal A, Ward EM. Increasing incidence of differentiated thyroid cancer in the United States, 1988-2005. Cancer 2009;115:3801-7.

3. Kweon SS, Shin MH, Chung IJ, et al. Thyroid cancer is the most common cancer in women, based on the data from population-based cancer registries, South Korea. Fpn 7 Clin Oncol 2013;43:1039-46.

4. Davies L, Welch H. Current thyroid cancer trends in the United States. 7AMA Otolaryngol Head Neck Surg 2014;140:317-22.

5. Canadian Cancer Society's Advisory Committee on Cancer Statistics. Canadian cancer statistics 2016. Special topic: HPV-associated cancers. Available: www.cancer. $\mathrm{ca} /$ /media/cancer.ca/CW/cancer\%20information/cancer\%20101/Canadian\%20 cancer\%20statistics/Canadian-Cancer-Statistics-2016-EN.pdf (accessed 2016 Nov. 24)

6. Liu S, Semenciw R, Ugnat A, et al. Increasing thyroid cancer incidence in Canada, 1970-1996: time trends and age-period-cohort effects. Br 7 Cancer 2001; 85:1335-9.

7. Davies L, Morris LGT, Haymart M, et al. American Association of Clinical Endocrinologists and American College of Endocrinology disease state clinical review: the increasing incidence of thyroid cancer. Endocr Pract 2015;21:686-96.

8. Black WC. Overdiagnosis: an underrecognized cause of confusion and harm in cancer screening. 7 Natl Cancer Inst 2000;92:1280-2.

9. Choosing Wisely Canada. Five things physicians and patients should question. Ottawa: Canadian Medical Association; 2014. Available: www.choosingwiselycanada.org/ recommendations/endocrinology-and-metabolism (accessed 2016 Sept. 30).

10. Canadian Cancer Society's Advisory Committee on Cancer Statistics. Canadian cancer statistics 2015. Special topic: predictions of the future burden of cancer in Canada. Available: www.cancer.ca/ /media/cancer.ca/CW/cancer\%20information/cancer\% 20101/Canadian\%20cancer\%20statistics/Canadian-Cancer-Statistics-2015-EN .pdf (accessed 2016 Nov. 24).

11. Statistics Canada. Causes of death 1970 to 1999: provinces by sex and Canada by sex and age. Ottawa: Statistics Canada. Cat no 84F0208XPB, 84-208, 84-203, 82-003S11.

12. CANSIM [database]. Table 051-0001: Estimates of population, Canada, provinces, and territories. Table 102-0522: Deaths, by cause, Chapter II: Neoplasms, age group and sex, Canada. Table 103-0550: New cases of primary cancer (based on the August 2015 CCR tabulation file), by cancer type, age group and sex, Canada, provinces and territories. Table 103-0553/4: New cases and 1991/2011 age-standardized rate for primary cancer (based on the August 2015 CCR tabulation file), by cancer type and sex, Canada, provinces and territories. Ottawa: Statistics Canada. Available: www5.statcan.gc.ca/cansim/ home-accueil?lang=eng\&p2=49\&MM (accessed 2016 Apr. 10).

13. Band PR, Gaudette L, Hill GB, et al. The making of the Canadian Cancer Registry: cancer incidence in Canada and it regions, 1969 to 1988. Ottawa: Canadian Council of Cancer Registries; 1993:16-21.

14. CANSIM [database]. Table 051-005. Estimates of population, Canada, provinces and territories. Ottawa: Statistics Canada. Available: www5.statcan.gc.ca/cansim/a26? lang=eng\&retrLang=eng\&id $=0510005 \& \&$ pattern $=\&$ stByVal $=1 \& p 1=1 \& p 2=31$ $\&$ tabMode $=$ data Table $\&$ csid $=($ accessed 2016 Nov. 22$)$

15. Hall SF, Irish J, Groome P, et al. Access, excess, and overdiagnosis: the case for thyroid cancer. Cancer Med 2014;3:154-61.
16. Vaccarella S, Dal Maso L, Laversanne M, et al. The impact of diagnostic changes on the rise in thyroid cancer incidence: a population-based study in selected high-resource countries. Thyroid 2015;25:1127-36.

17. Vaccarella S, Franceschi S, Bray F, et al. Worldwide thyroid-cancer epidemic? The increasing impact of overdiagnosis. N Engl 7 Med 2016;375:614-7.

18. Schonfeld SJ, Lee C, Berrington de Gonzalez A. Medical exposure to radiation and thyroid cancer. Clin Oncol (R Coll Radiol) 2011;23:244-50.

19. Zimmermann MB, Galetti V. Iodine intake as a risk factor for thyroid cancer: a comprehensive review of animal and human studies. Thyroid Res 2015;8:8.

20. Enewold L, Zhu K, Ron E, et al. Rising thyroid cancer incidence in the United States by demographic and tumor characteristics, 1980-2005. Cancer Epidemiol Biomarkers Prev 2009;18:784-91.

21. Kitahara CM, Platz EA, Freeman LB, et al. Obesity and thyroid cancer risk among U.S. men and women: a pooled analysis of five prospective studies. Cancer Epidemiol Biomarkers Prev 2011;20:464-72.

22. Kent WD, Hall SF, Isotalo PA, et al. Increased incidence of differentiated thyroid carcinoma and detection of subclinical disease. CMA7 2007;177: 1357-61.

23. Pakdaman MN, Rochon L, Gologan O, et al. Incidence and histopathological behavior of papillary microcarcinomas: study of 429 cases. Otolaryngol Head Neck Surg 2008;139:718-22.

24. Hay ID, Hutchinson ME, Gonzalez-Losada T, et al. Papillary thyroid microcarcinoma: a study of 900 cases observed in a 60-year period. Surgery 2008;144:987-8.

25. Hall SF, Walker H, Siemens R, et al. Increasing detection and increasing incidence in thyroid cancer. World 7 Surg 2009;33:2567-71.

26. Furuya-Kanamori L, Bell KJL, Clark J, et al. Prevalence of differentiated thyroid cancer in autopsy studies over six decades: a meta-analysis. 7 Clin Onco 2016;34:3672-9.

Affiliations: School of Public Health (Topstad), University of Alberta, Edmonton, Alta.; Department of Family Medicine and Department of Community Health Sciences (Dickinson), University of Calgary, Calgary, Alta.

Contributors: James Dickinson originated the study questions. Dawnelle Topstad analyzed the data and wrote the first draft of the article. Both authors interpreted the data, revised the article and gave final approval of the version to be published.

Funding: James Dickinson received a grant from the Public Health Agency of Canada through the office of the Canadian Task Force on Preventive Health Care to obtain the data used in this study. Dawnelle Topstad receved a grant from the Global Health Fund at the University of Alberta School of Public Health for data retrieval.

Acknowledgement: The authors thank Virginia Goetz for assistance in transcribing and organizing data.

Supplemental information: For reviewer comments and the original submission of this manuscript, please see www.cmajopen.ca/content/5/3/ E612/suppl/DC1. 